\title{
What the Disjunctivist is Right About
}

\author{
Alan Millar \\ University of Stirling
}

\section{Introduction}

There is a success element to seeing, or at least to seeing conceived in a very familiar way. If I see a cat, under this conception, then a cat must be there before me. But I could seem to see a cat even if no cat were there. To deal with this a certain concept of a visual experience is commonly introduced. The idea is that if for me it is just as if I am seeing a cat then this will be so in virtue of my having a visual experience of a certain kind. It will be an experience such that it looks to me just as if a cat is before me. I could have such an experience when seeing a cat and I could have such an experience (indeed, the very same experience) when merely hallucinating a cat. Obviously then having an experience, so understood, is not sufficient for seeing a cat. According to the standard causal theory of perception, if I see a cat then that cat must be there before me and my having an experience of the right kind must be caused, in some appropriate way, by its being there before me. I shall call the conception of experience that is part of this picture the traditional conception. It figures in key writings on causation and perception and is still very widely held. (See Grice 1961, Strawson 1974, 1979, Pears 1976, Searle 1983 and many others subsequently.) Over the last twenty to thirty years or so, this conception has been subjected to criticism by philosophers who advance, or 
who are at least sympathetic towards, a disjunctive conception of experience. ${ }^{1}$ We shall come to the details presently. The main critical target of disjunctivists is the following assumption:

Subjects who on seeing $\mathrm{X} /$ an F/something $\mathrm{G}$ have an experience such that it looks to them just as if $\mathrm{X} / \mathrm{an} \mathrm{F} /$ something $\mathrm{G}$ is there could have the very same experience if they were merely hallucinating X/an F/something G.

The disjunctivist holds, by contrast, that perceptual experiences - the experiences we have when perceiving worldly objects — and merely hallucinatory experiences, are different in kind. The former are intrinsically encounters with worldly objects; the latter are not. Despite recent interest it is fair to say that neither disjunctivism itself nor the dispute between disjunctivists and traditionalists has secured a firm place in mainstream theory of knowledge. ${ }^{2}$ My aim here is to distil out some points of real importance from disjunctivist thinking. I find that for many philosophers the disjunctivist stance is puzzling or at least under-motivated. By laying out key elements of the stance clearly I hope to make them less puzzling. I also aim to show that it is possible to take on board what is right in the stance, while still making sense of our having perceptual knowledge of objects, scenes and events in keeping with the traditional conception. There is a price to be paid for this accommodation: we need to abandon the idea that experiences can bear the explanatory burden that disjunctivists have placed on them. They have a role in accounting for perceptual knowledge. That much is obvious. But this role is part of a wider picture that can incorporate the

\footnotetext{
${ }^{1}$ See Hinton 1973, Snowdon 1980-81, 1990 and 2002, McDowell 1982, 1986 and 1995, Hyman 1992 and 1994, Child 1994, Putnam 1994, Brewer 1999, Williamson 2000, Campbell 2002, Martin 2004. Child's discussion contains a lucid overview of earlier thinking.
} 
traditional conception. The upshot is that at least on epistemological matters the gap between traditionalists and disjunctivists can be narrowed.

\section{Disjunctive analyses}

A good place to start is Paul Snowdon's attack on a familiar argument for the standard causal theory of perception. (Snowdon:1980/81; 1990) The familiar argument rests on examples designed to show that having an experience such that it is just as if an $\mathrm{F}$ is before one, when there is an F before one, is not sufficient for perceiving an F (Grice 1961, Pears 1976). The examples are of imagined scenarios in which the subject has a veridical hallucination-a hallucinatory experience such that, coincidentally or by some devious contrivance, things are as they appear to the subject. What is missing from the examples, we are invited to conclude, is an appropriate causal chain linking the object, scene, or event in question to the having of the experience. Snowdon's main move is to argue that the conception of experience presupposed by this way of thinking — what I have called the traditional conception —is not mandatory.

Here I am looking at cat, which as it happens is curled up on the sofa, with light shining in from a window on my left. Various looks-specifications apply to me in this situation, including along with many others: it looks to ... just as if a cat is there; it looks to ... as if a cat is curled up on the sofa; it looks to ... as if light is shining in from a window on my left. Now consider the hallucinatory counterpart to my current experience-a possible hallucinatory experience $\boldsymbol{e}$ such that every looks-specification that applies to me in virtue of my current visual experience would also apply to me in virtue of my having $\boldsymbol{e}$, and vice versa.

\footnotetext{
${ }^{2}$ I am judging here from the contents of recent anthologies and introductory works in epistemology. Critical discussions can be found in Robinson 1990 and 1994, P. Smith 1990/91, Millar 1996, Sturgeon 2000, Foster
} 
What Snowdon thinks open to dispute is that my actual experience and its hallucinatory counterpart would be one and the same experience. This may initially look like a startling move, at least to those schooled in the traditional conception, since sameness with respect to the applicability of looks-specifications might seem to guarantee sameness of experience. But the whole point of Snowdon's move is to resist the idea that it is obvious that the experiences under consideration — perceptual experiences and their hallucinatory counterparts—are individuated by how it looks to the subject as if things are. Drawing upon an earlier discussion by J. M. Hinton (1973), he argues that there is a disjunctive account of looksjudgements (judgements in which a looks-specification is applied to a subject) that does not presuppose that experiences are so individuated. Here is one way in which he captures the disjunctive account:

[L]ooks-judgements are made true by two types of occurrence: in hallucinations they are made true by some feature of a (non-object-involving) inner experience, whereas in perceptions they are made true by some feature of a certain relation to an object, a noninner experience, (which does not involve such an inner experience). (Snowdon 1990: 130)

The view can be refined to accommodate a wider range of disjuncts. The idea is that the judgement that it looks to me just as if a cat is curled up on the sofa might be made true either by my seeing a cat on the sofa, or by my seeing on the sofa something looking as if it is a cat, or by my hallucinating a cat on a sofa, or by ... ${ }^{3}$ A merely hallucinatory experience of a cat

2000, Ayers 2002, A. D. Smith 2002, Johnston 2004, Thau 2004, Fish 2005.

${ }^{3}$ Note that the notion of looks figuring in the open-ended disjunction of situations that might make it true that it looks to me as if a cat is on the sofa is not the same as the notion of looks in the statement for which the disjunction is supplying possible truth-makers. 
on a sofa—one that does not involve any perceptual encounter with objects — would be a nonobject-involving inner experience. Seeing a cat on the sofa would be a non-inner experience - an experience that consists in a perceptual encounter with objects. Crucially, we are not to think of the having of an experience that consists in an encounter with objects as decomposable into the having of an inner non-object-involving experience plus the obtaining of a suitable causal relation between objects and the having of that inner experience.

I have so far left out of account an element of Snowdon's picture that is important for his purposes. The causal theory that he considers is a partial conceptual analysis of seeing. According to the theory, so understood, it is built into the ordinary notion of seeing an $\mathrm{F}$ that people see an F only if they have a certain kind of (inner) experience standing in an appropriate causal relation to an F. If the theory were correct then, it would seem that, in order to understand what it is to see an F we would need first to understand what it is for it to look to one just as if an $\mathrm{F}$ is there. That looks implausible. The most natural way to explain the notion of its looking to a subject just as if an $\mathrm{F}$ is there is by reference to cases in which the subject sees an F. (This is how I introduced the notion above.) If you know what it's like to see an $\mathrm{F}$ then you can grasp the idea of its being for you just as if you see an F, irrespective of whether you do. ${ }^{4}$ This latter idea is just the idea of its looking to you as if an F is there. Now, if the notion of its looking to one just as if an $\mathrm{F}$ is there is conceptually dependent on the notion of seeing an $\mathrm{F}$, then it is hard to see how the latter notion can be given a conceptual analysis in terms of the former. It is a further matter, however, whether this problem provides a reason to reject the view that the experience you have as you look at an F and the hallucinatory counterpart of that experience could be one and the same experience. For even if the concept of seeing an $\mathrm{F}$ is conceptually prior to the notion of its looking to one just as if an $\mathrm{F}$ is there, it could be that part of what is happening when one sees an F is that one has an

\footnotetext{
${ }^{4}$ For a somewhat similar line of thought, see Child 1994: 144.
} 
experience under the traditional conception. Indeed, it could be that the best explanation for the phenomenon of seeing is in terms of a theory that posits such experiences.

\section{Intermediaries}

What I have called Snowdon's main move does not, and is not meant to, provide a reason for rejecting the traditional conception. It sets out what seems to be a coherent way of thinking of the experiences implicated in perception on which those experiences are not individuated in terms of looks-specifications. The point is that if the view is coherent then its availability suggests that we may not infer, without further ado, from

(i) Every looks-specification that would apply to a subject A in virtue of A's having experience $\boldsymbol{e}^{1}$ would apply to A in virtue of A's having $\boldsymbol{e}^{2}$, and vice versa,

to

(ii) $\boldsymbol{e}^{1}$ and $\boldsymbol{e}^{2}$ are one and the same experience.

From Snowdon's standpoint, for all that (i) tells us, $\boldsymbol{e}^{1}$ might be intrinsically an encounter with an object and $\boldsymbol{e}^{2}$ might be a mere hallucination. In that case $\boldsymbol{e}^{1}$ and $\boldsymbol{e}^{2}$ would, for Snowdon, be different experiences. $\boldsymbol{e}^{1}$ would be essentially relational since to have it is to stand in a relation to some object or objects; $\boldsymbol{e}^{2}$ would not be. Given that traditionalists acknowledge that seeing, in the success sense, is intrinsically an encounter with objects, it might seem that the issue here is purely terminological. While traditionalists recruit the term 'experience' for something the having of which falls short of constituting seeing, the friends 
of disjunctivism use the term for something that constitutes seeing. But the issue is not purely terminological. It is crucial to the thinking that lies behind disjunctivism that seeing, as a perceptual encounter with worldly objects, does not implicate any inner experiential state that could also be had when not encountering such objects.

Why should it be thought that the disjunctivist conception of experience, and the related conception of experiences in perception as essentially relational, is to be preferred to the traditional conception? There is no doubt that an important source of motivation is the thought that there is no prospect of giving a plausible account of perceptual knowledge in terms of the traditional conception. It is this source that is the focus of the present discussion.

One way of giving expression to the supposed problem is in terms of the idea that the traditional conception, in one way or another, takes our perceptual encounters with the world to involve intermediaries. The worry is that if perception directly acquaints us only with intermediaries that interpose between us and the world, then it is difficult to see how we can have epistemic access to what lies beyond them. John McDowell links the invocation of intermediaries to a certain 'tempting' line of thought that he represents as a version of the argument from illusion. Suppose that we have a capacity to tell by experience that such-andsuch is so. The tempting line is as follows:

In a deceptive case, what is embraced within the scope of experience is an appearance that such-and-such is the case, falling short of the fact: a mere appearance. So what is experienced in a non-deceptive case is a mere appearance too. The upshot is that even in the non-deceptive cases we have to picture something that falls short of the fact ascertained, at best defeasibly connected with it, as interposing itself between the experiencing subject and the fact itself. (McDowell 1982/1998: 386). 
This is not so much a determinate line of thought as a schema for a certain style of argument. It is meant to cover, among others, arguments that apply to situations in which the problematic character of perception is not at issue. Indeed, in the article from which the passage is drawn McDowell is primarily concerned with the epistemological problem of other minds. From looking at Sally's behaviour I might judge that she is anxious. Suppose that she is. According to the tempting line, since Sally might have displayed the same behaviour even if she had not been anxious, the behaviour is a 'highest common factor' between the actual case, in which Sally is anxious, and a deceptive case in which she displays the same behaviour but is not anxious. So, the argument goes, it cannot be the case that my perceptual experience as I look at Sally embraces the fact that she is anxious. At best my experience embraces something that falls short of this fact — the fact that she displays the behaviour in question, and thus appears to be anxious. In this example the intermediary is not something interposing between the subject and the world. It is a worldly appearance-Sally's appearing in virtue of her behaviour to be anxious — conceived as being perceptually accessible to the subject and yet interposing itself between the subject and something that lies out of direct perceptual reach-Sally's actually being anxious. But McDowell clearly takes a further application of the schema to lead to the conclusion that no worldly facts are embraced by perceptual experience and no worldly objects picked out directly by perceptual consciousness. This is explicit in the following passage:

If the object of experience is in general a mere appearance, as the 'highest common factor' model makes it, then it is not clear how ... we could save ourselves from having to picture it as getting in the way between the subject and the world. (McDowell 1982/1998: 388. $)^{5}$

\footnotetext{
${ }^{5}$ See also the same article on pp. 392-93.
} 
If this is right no perceptual experience can embrace a worldly object, since the having of any such experience is compatible with the absence of any such object. So no such experience can embrace facts about worldly objects either. Looking at the cat my current experience cannot embrace it or the fact that something before me so much as looks like a cat. As McDowell puts it in another place, 'subjectivity is confined to a tract of reality whose layout would be exactly as it is however things stood outside it, and the commonsense notion of a vantage point on the external world is now fundamentally problematic' (1986/1998: 241). McDowell thinks the tempting line of thought, in all its forms, can be resisted with the help of a disjunctive conception of appearances, according to which 'an appearance that such-and-such is the case can be either a mere appearance or the fact that such-and-such is the case making itself perceptually manifest to someone' (McDowell 1982/1998: 386-87). My immediate concern is not with this particular version of disjunctivism but with whether the traditionalist is committed to positing the intermediaries that are taken to make perceptual knowledge problematic. ${ }^{6}$ Applied to perceptual cases generally, the tempting line looks rather like arguments that were used for the conclusion that in perceptual experience we encounter, not physical objects, but sense-data, where these are conceived as something inner. (This is not surprising given that McDowell takes it to be a version of the argument from illusion.) It is open to traditionalists, however, to reject the idea that they are committed to positing sense-data in this sense. The bottom line for the traditionalist is that for any case of seeing an F there is a hallucinatory counterpart in which a subject has exactly the same experience and yet does not see an F. There is indeed a common factor in the two cases - one and the same experience is implicated. But the common factor so conceived is not a common object of 
perception. (Millar 1996 deploys this consideration in a critical discussion of disjunctivism.) Even so, the traditionalist might seem to be committed to rejecting direct realism, the view that we can, and regularly do, perceive worldly objects directly and not via perception of something inner. For surely if seeing an F on some occasion implicates a certain experience, and if the having of that experience is compatible with not seeing an $\mathrm{F}$, then seeing an $\mathrm{F}$ is in some sense mediated by the having of that experience. It matters though what is meant by 'mediated'. Traditionalists can make use of a distinction invoked by John Foster between psychological mediation and perceptual mediation (Foster 2000: 4-14). We have perceptual mediation when 'the perceiving of one thing is wholly channelled through the perceiving of another', that is, when one perceives $X$ in virtue of the fact that one perceives $Y(X \neq Y)$, and certain additional facts (Foster 2000: 4, omitting refinements). By contrast, my perceiving X is psychologically mediated by my having an experience $\mathrm{E}$, if my having $\mathrm{E}$ is not itself a state of perceiving $\mathrm{X}$ and the fact that I perceive $\mathrm{X}$ breaks down into the fact that $\mathrm{I}$ have $\mathrm{E}$ and certain additional facts. (Foster 2000: 10, again with refinements omitted.) Traditionalists must concede that perception of objects is psychologically mediated but their bottom line on experience does not commit them to holding that perception of worldly objects is perceptually mediated. Further, they may hold that while perceptual mediation involving perception of something inner may be epistemologically problematic, psychological mediation is epistemologically innocent and compatible with direct realism. ${ }^{7}$

\footnotetext{
${ }^{6}$ In Millar (forthcoming) I explore the relationship between McDowell's style of disjunctivism, which is formulated with epistemological issues in mind, and that of Snowdon for whom the focus is on the character of perceptual experience as an issue in the philosophy of mind. On this, see also Snowdon 2005.

${ }^{7}$ They will, however, resist the idea that they are Naïve Realists in Mike Martin's sense. For Martin Naïve Realism is not simply the view that we perceive some objects in a perceptually unmediated manner; it entails that '[s]ome of the objects of perception - the concrete individuals, their properties, the events these partake in - are constituents of the experience' (2004: 39).
} 
This last move might seem a little too quick. The idea of perceptual mediation is quite a strong one. Sense-datum theorists who believe that perception of worldly objects is indirect need not be committed to thinking that our relation to the sense-data that play a mediating role is properly described as perceiving. They may think, for instance, that our awareness of our sense-data is to be distinguished from perception. It might be called direct apprehension. ${ }^{8}$ The important issue, however, if whether sense-data are conceived as inner objects that are given to the experiencing subject as objects of consciousness - the only objects directly encountered when one perceives worldly objects. If they are then a variant of Foster's distinction still has a point. What contrasts with psychological mediation might be called objectual mediation. Perception of $\mathrm{X}$ is objectually mediated if it is through direct apprehension of some other item that, provided certain additional facts obtain, the subject perceives X. It is open to traditionalists to plead not guilty to the charge that they are committed to thinking that perception of worldly objects is objectually mediated by direct apprehension of anything inner. Their view is that we perceive objects through having experiences, not through directly apprehending either the experiences or anything inner that is presented through having the experiences. ${ }^{9}$

The approach just outlined will not satisfy critics of the traditional conception, however. Hilary Putnam argues that the direct realism accommodated by the standard causal theory is

\footnotetext{
${ }^{8}$ Note, however, that G. E. Moore (1953) used the term 'direct apprehension' and considered direct apprehension to be a form of perception. He also gives qualified approval to the view that sense-data are inner in that they occupy the private spaces of the minds of individuals. See especially 1953: ch. II and the beginning of ch. III.

${ }^{9}$ The view raises an issue about how to explain what makes sensory experiences conscious if not our being in some manner aware of them. Whether what makes a state conscious is the subject's being aware of $i t$ is debatable. Traditionalists might adopt Fred Dretske's view what makes states conscious is their enabling their subjects to be aware, or bringing it about that they seem to be aware, of something else. Dretske writes, '[M]y visual experience of a barn is conscious, not because I am introspectively aware of it ... but because it (when
} 
pretty thin beer and hardly worthy of the name. According to what he prefers to call natural realism - a view he finds in William James - 'successful perception is just a seeing, or hearing, or feeling, etc., of things "out there", and not a mere affectation of a person's subjectivity by those things' (Putnam 1994: 454). This succinctly captures a thought that is a central focus of attention in the present discussion - that perceiving is not 'a mere affectation of a person's subjectivity' by the presence of objects in the world around us.

Those advancing Putnam's critique face a challenge too. The challenge is to spell out what exactly is missing from an account of perception that explains seeing, for instance, just in terms of having a suitably caused visual experience. It is not enough to say that 'successful [seeing] is just a seeing ... of things "out there", since that is not something that traditionalists who adopt a causal theory of perception are committed to denying. Nor is it enough to add, as Putnam does in the same context, that seeing is not analysable. For that does not pinpoint what it is about seeing that is left out of account on the standard causal theory. We come closer to the intuition that drives Putnam's critique with the second conjunct of the idea that he attributes to James in the following:

James's idea is that the traditional claim that we must conceive of our sensory experiences as intermediaries between us and the world has no sound arguments to support it, and, worse, makes it impossible to see how persons can be in genuine cognitive contact with a world at all. (Putnam 1994: 454) ${ }^{10}$

brought about in the right way) makes me aware of the barn' (1993: 280). I do not suggest that this is problemfree but do not pursue the matter here.

${ }^{10}$ McDowell (1995/1998: 403) speaks of a 'cognitive purchase on an objective fact' in a passage designed to make us feel the oddity of theories of knowledge linked to the traditional conception. Scott Sturgeon (2000: 31) 
Suppose it is conceded that the worry about intermediaries, as so far presented, can be met by acknowledging, in the spirit of Foster's distinction, that while experiences mediate perception of objects psychologically, they do not do so objectually. Still, Putnam's comment is suggestive of a more serious challenge to the traditionalist: to show how to reconcile the idea that perception is psychologically mediated with the idea that it enables us to make cognitive contact with the world. Of course, more needs to be said to make clear why it might be thought that psychological mediation is incompatible with cognitive contact. I turn to this in the next section and then explain the attraction of a relational conception of experience for those who place weight on the metaphor of cognitive contact.

\section{The significance of cognitive contact}

One source of the worry about genuine cognitive contact comes from linking the traditional conception to a particular way of thinking about knowledge. Suppose we think of knowledge as requiring justified true belief. Then we might wonder how it is that I acquire the knowledge that a cat is there as I look at the cat. For as I look it simply strikes me that a cat is there. My belief to this effect is not arrived at through a process of reasoning - it is not a conclusion from prior assumptions. That raises the question, 'What provides the justification for my belief?' A common answer is that the belief is justified because it is grounded in my current visual experience. ${ }^{11}$ But what if we think of my experience along the lines of the traditional conception? Under this conception it is possible to have the very experience I am having now when no cat is there. Suppose that my justification derived from having an experience so conceived. Then I could be in the same justificatory position as I am in now, in 
the good situation in which I see the cat, if I was in a corresponding bad situation in which I have the same experience but no cat is there. With respect to justification there would be parity between the two situations.

The foregoing remarks deal with a simple version of the view under consideration, according to which in the good situation my belief that a cat is there is justified simply in virtue of being based on my current visual experience. A more plausible view would recognise further factors bearing on the justificatory status of my belief. For instance, it might be held that the experience confers justification on my belief only so long as I have no reason to think that there are countervailing facts - facts that provide a reason not to take how it looks to me that things are as the way they are. But if the additional factors bearing on justification are ones that could obtain in a corresponding bad situation-one in which I have the same experience but no cat is there - there would be parity between that situation and the good situation with respect to justification. Why should we balk at this?

This is where the metaphor of cognitive contact comes into play. Coming to know that $\mathrm{p}$ through, say, seeing that $p$, is coming into cognitive contact with the fact that $p$ through the exercise of one's visual-perceptual and recognitional capacities. Contact in virtue of seeing that $\mathrm{p}$ implies some real connection between the fact that $\mathrm{p}$ and one's coming to believe that p. The trouble for the sort of view just outlined is that the fact that I am justified in believing that $\mathrm{p}$ in the good situation, and that it's true that $\mathrm{p}$ in that situation, does not guarantee that there is a real connection between me and the fact that $\mathrm{p}$. Essentially the same problem arises for any version of what McDowell (1995/1998) has called a hybrid conception of knowledge - a conception according to which true belief is turned into knowledge by the satisfaction of conditions which could be satisfied when the truth requirement for knowledge is not met. It arises, for instance, in thinking of perceptual knowledge in terms of true belief

\footnotetext{
${ }^{11}$ See for instance Pollock 1987: 175-79, Alston 1999, Audi 2003: 28.
} 
formed via the operation of a belief-forming process of a sort that reliably yields true beliefs. There will be good situations and corresponding bad situations that are on a par with respect to the status conferred by the operation of the reliable process, so long as the process is individuated in such a way that it can be in operation in forming the belief that $\mathrm{X}$ is there when $\mathrm{X}$ is not there. (For theorists who favour a reliabilist view of justification this would, of course, amount to parity with respect to justification). The fact that a belief is true, and has the status conferred by its having come about through the operation of the reliable process, does not guarantee that there is any cognitively relevant connection between having the belief and the fact that makes it true. The metaphor of cognitive contact helps to pin down what at least some critics of the traditional conception of experience think is wrong with that conception: when we try to account for perceptual knowledge in terms of that conception we cannot to justice to the metaphor.

A very natural response to the problem is to build a causal condition into the account of knowledge, at least for cases of perceptual knowledge. Consider a variant of a much-used Gettier-type example. As I approach the open door of a house I seem to see Bill and, having no reason to think otherwise, believe that he is there before me. Unknown to me I am looking at a life-size photograph of him, but for a few moments it looks to me just as if he is standing in front of me. As it happens he is in front of me but hidden from view behind the photograph. If this is indeed a Gettier-type example then it has to be a case in which there is justified true belief but no knowledge. Certainly there is a sense in which it could be reasonable for me to believe that Bill in there in this situation. After all, momentarily it is just as if he is there and I might have no reason to suppose that there are any countervailing facts. If that is what it takes to be justified, I can be justified in this situation. It might be suggested that the explanation of why it is not a case of knowledge is that there is no causal connection between the presence of my friend and my having experiences such that it looks to me just as 
if my friend is there. Cognitive contact, I said, requires connection. If there were an appropriate causal connection between the presence of Bill and my having the experiences, and between my having the experiences and forming the belief, then there would be a connection of a sort that looks relevant. The trouble now is that this will not, and should not, satisfy the critics of the traditional conception of experience. Requiring that a causal condition should be satisfied for perceptual knowledge looks like ad hoc stipulation in the absence of some account of why the satisfaction of the condition helps to explain why it is knowledge that is acquired. Apart from that, the insertion of causal conditions will seem to defenders of a relational conception of experience to put subjects at a distance from the world that is epistemologically problematic. If an experience that could be had in the absence of Bill psychologically mediates my seeing Bill then having it clearly does not suffice to make Bill available to me as an object of thought and knowledge. It is not clear how the fact that I am caused to have it by the presence of Bill can make Bill available to me as an object of thought and knowledge. Bill, after all, is the distal cause of my having the experience. Given a relational conception of experience there is no distance-Bill is a constituent of my experience in the good case. With this in mind even psychological mediation can seem to put us at a distance from the objects we know about perceptually.

My aim now is further to understand this line of thought and thereby the appeal of the relational conception of experience that is part of the disjunctivist's picture.

\section{Making sense of cognitive contact}

The idea I shall explore is that to make sense of perceptual knowledge, and why it should be thought to implicate cognitive contact as conceived by the disjunctivist, we need to take into account an intimate connection between perception and demonstrative judgement. Ways of 
thinking about this connection, which are conducive to the disjunctivist standpoint, are variously explored by Gareth Evans (1982), John McDowell (1986), Paul Snowdon (1992), Bill Brewer (1999) and John Campbell (2002). Closely related themes are pursued by William Child (1994). I shall not attempt an exposition of their detailed lines of thought. I shall instead focus on the following claims:

(A) Perceptual knowledge depends on being able to have de re thoughts about perceptually presented objects: we have to be able to think of such objects that they are such-andsuch.

(B) The relevant thoughts are relational demonstrative thoughts that essentially depend on the presence of the objects they pick out: if I think of X that it is G, no thought would be that thought unless $\mathrm{X}$ was present. ${ }^{12}$

(C) A correct account of the experiences implicated by perceptions of objects, scenes, and events must enable us to understand how it is that by means of those perceptions we are able to grasp certain demonstrative thoughts and make certain demonstrative judgements.

\footnotetext{
12 There are conceptions of de re thoughts (e.g., Bach 1982) on which, considered psychologically, such thoughts are indexical and determine semantic content only through being had in a context. Under such views de re thoughts about a perceived object would not be relational demonstrative thoughts in the sense intended here. Pressure to resist the relational view of demonstrative thought comes from the assumption that a proper taxonomy of propositional attitudes would individuate them non-relationally. On this, see Fodor 1987: ch. 2. Relationalists, of course, reject this assumption.
} 
(D) Condition (C) is met only if the experiences implicated in perception are, intrinsically, encounters with what is in the world around us.

Assumption (A) is uncontroversial. Suppose that this time, approaching the open door in the setting that figured in the photograph case, I do see Bill and thereby come to know that he is there. My knowing that Bill is there by looking requires that my seeing him enables me to think of him as that such-and-such and as there. I need to be able to have de re thoughts about him and about that location — thoughts that are made possible by my seeing him..

(B) links the relevant de re thought to a particular conception of demonstrative thought upon which disjunctivists rely. If I have the visual-perceptual demonstrative thought, That is Bill, it is essential to my having that very thought that it picks out a suitably located objectone that my perception presents to be so located. Were there no object so presented I would not be having that very thought even though I could give expression to my current state of my mind by saying, 'That is Bill'. Linked to this view is a disjunctive account of the mentality given expression by sincere utterances of sentences like, 'That is Bill'. Someone who sincerely utters, 'That is $\mathrm{X}$ ' might be giving expression to a demonstrative judgement, That is $X$, and thereby pick out an object, or might be giving expression to a deceptive counterpart of such a judgement - a distinct state of which it is not true that it picks out X. (Cf. McDowell 1986.) This approach to demonstrative judgement is controversial. But since my aim is to see whether disjunctivist thinking that incorporates it can be squared with a traditional conception of experience, I shall take it for granted in what follows.

(C) is uncontroversial given (B). We are interested in how perceiving an object makes it possible to have demonstrative thoughts about that object. An acceptable account of the experiences implicated on some occasion of seeing must make it possible to understand the 
role of those experiences in enabling us to have demonstrative thoughts about what is perceived.

(A), (B), and (C) together serve to explain why at least some disjunctivists take the metaphor of cognitive contact seriously. It is in virtue of enabling us to pick out objects in thought that visual perception puts us in cognitive contact with those objects and enables us to take in facts about those objects. If via perception there were no demonstrative thoughts about objects there would be no cognitive contact with those objects.

We are now very close to the heart of the matter. But we still need to consider the motivation for accepting (D). The relational conception of demonstrative thought dictates a disjunctivist conception of the mentality which can be given expression by utterances like, 'That is Bill'. This disjunctivism is at the level of thought and so, one might think, not at the level of experience. We still need to make explicit why we should discriminate between essentially object-involving experiences and non-object-involving experiences. Suppose then that experiences were not intrinsically encounters with objects. Then the experience I have when I see Bill would not be intrinsically an encounter with Bill. In that case, the argument goes, it is not something that explains why the presence of Bill is open to view for me, making Bill an object about which I can have demonstrative thoughts and make demonstrative judgements. For since I could have the very same experience if Bill had not been not there, the having of that experience cannot by itself explain why I am able to have demonstrative thoughts, and make demonstrative judgements, about Bill.

This helps to explain further why even psychological mediation is thought by the disjunctivist to be epistemologically problematic. A picture on which experiences as traditionally conceived psychological mediate my seeing that Bill is there is thought to put me at a distance from what I am supposed to know. (Recall the remarks towards the end of section 4 above.) This is not because experiences are encountered intermediaries. (Let's take 
it to be conceded that the traditionalist's protests on that score are justified.) It is because experiences under the traditional conception do not explain how perception enables us to have demonstrative thoughts and knowledge. The relational conception of perceptual experiences removes the distance. My perceptual experience as I look at Bill can be an unmediated spotting of Bill and an unmediated taking-in of the fact that he is there.

This serves to bring out what I take to be right in disjunctivism. The disjunctivist is right in thinking that we cannot adequately explain how perception enables us to pick out objects demonstratively simply in terms of our having experiences under the traditional conception. I shall assume here that the disjunctivist is also right in giving demonstrative thought a central place in the theory of perceptual knowledge. But there are two options by way of response to these concessions. One, adopted by the disjunctivist, is to suppose that we need an alternative conception of experience - a conception on which perceptual experiences are essentially relational and can therefore bear the explanatory burden placed on them by disjunctivists. The other, which remains open to the traditionalist, is to show that experiences do not have to bear the heavy explanatory burden that disjunctivists place upon them and that we can explain how perception makes it possible to have demonstrative thoughts and demonstrative knowledge even under the traditional conception. I develop the second of these options in the next section.

\section{Cognitive contact under the traditional conception}

The traditionalist needs to account for the asymmetry in epistemic status between

(a) a case in which a subject has a true belief that is reasonable, even though he or she is not in cognitive contact with the fact that makes the belief true, and, 
(b) a corresponding case in which there is genuine cognitive contact with the fact.

The situations might be, respectively, the Gettier-type example of my believing that Bill is there on looking at the photograph and the situation in which the setting is much the same except that there is no photograph and I see Bill and thereby come to know that he is there. It is crucial that in the latter situation it is not simply that I am affected by the presence of Bill. I discriminate the object that is Bill. This is visual discrimination consisting in my being furnished with a flow of visual experiences that prime me to respond behaviourally to this object in ways that are appropriate to its size, shape, and location. It is the kind of discrimination that primes me not to bump into people and door posts as I walk along a corridor. I envisage it as being sub-doxastic, in that its outputs are not beliefs but visual experiences that prime me to behave in this or that way, depending on what I am doing. In the case in hand the exercise of capacities for visual discrimination make Bill available to me as a possible object of thought so that, if I suitably direct my thought, I can think about him. Given the appropriate recognitional capacity I am also enabled to recognise this Bill as Bill, so that I am primed to respond to his presence intellectually in ways appropriate to his being Bill. For instance, I can refer to him in conversation as being present. Both the discrimination and the recognition result from the exercise of capacities I have to do such things. At least part of the story of why, when I look at Bill, I am in cognitive contact with him, and facts about him, is that I have exercised those capacities. The contact, then, is not simply a matter of my being affected in certain ways as a result of the presence of Bill before me. It is a matter of being in a relational state in virtue of the exercise of those capacities. The exercise of the capacities is integral to my being in cognitive contact with Bill and with the fact that he is Bill. 
When I look at Bill in the doorway I have an experience such that it looks to me as if Bill is there. The disjunctivist is right to think that having such an experience under the traditional conception cannot account for what enables me to discriminate Bill perceptually or recognise him as Bill. As suggested above, I count as having done those things only if I have exercised appropriate capacities. But that is not a reason for supposing that no experience under the traditional conception has occurred. It is simply a reason not to look for an explanation of my cognitive contact with Bill, and with the fact of his being present, purely in terms of the occurrence of the experience. My cognitive contact with Bill comes from encountering him perceptually, in this case by seeing him. But my seeing him is not simply my having the experience; nor is it my having the experience because of the presence of Bill, since, in Putnam's terms, 'a mere affectation of my subjectivity' brought about by the presence of Bill falls short of being in cognitive contact with him. As suggested, it is a matter of my having exercised a discriminative capacity, as a result of which Bill is available to me as a possible object of thought, and a recognitional capacity as a result of which I recognise Bill as Bill.

On this approach experiences undoubtedly have a role in explaining what is going on when I know through seeing that Bill is there. (How could it be otherwise?) Experiences shape the thinking that, when things go well, puts me in cognitive contact with Bill and with the fact that he is there. I knew that he was there by looking because I exercised an appropriate discriminative capacity, and thereby saw him, and exercised a recognitional capacity, whereby I could tell that Bill was there. My exercise of the recognitional capacity was a response to my having visually discriminated Bill, but the exercise did not simply consist in my responding to the experience thus gained with the formation of a belief. It consisted in my recognising something seen as Bill. The same capacity would not have been exercised if I had been in the Gettier situation in which the photograph interposes between Bill and me. So there is an important asymmetry between such a situation and that in which I 
saw and recognised Bill. This is the asymmetry that had to be explained to do justice to the cognitive contact that there is in the good case. It can be explained in keeping with the traditional conception.

How should we think of the recognitional capacities on the view I have been outlining? Consider my capacity to tell that something is a sparrow by looking. I suggest that I have such a capacity in virtue of being so primed that if suitably prompted I would implement a certain judgement-forming procedure. Roughly speaking, the procedure is that whereby, under certain conditions (for instance, I don't believe that the object is too far away, or that the light is too poor, or that my eyes are not up to the job in hand) I judge either that the thing I am looking at is a sparrow, or that it is not, by way of immediate (non-inferential) reaction to some range of visual experiences that I have. Implementation of the procedure might be prompted by my wanting to tell whether or not the thing is a sparrow or simply by my attention being so engaged by what I see that the relevant procedure comes into play. Though non-inferential, the procedure implicates certain complex sensitivities on my part. For instance, I am sensitive to whether or not the conditions are suitable and so to whether or not I have a clear enough view of what I am looking at. I am also sensitive to the possibility of mistaking female sparrows for females of other species. That sensitivity is informed by knowledge of sparrows and of other birds likely to appear in my area. Note that the role of such sensitivities here is compatible with the view that I tell just by looking. Telling just by looking contrasts with telling by inference or the weighing up of evidence. It does not rule out the possibility that a sophisticated recognitional capacity is deployed, which is informed by knowledge and past experience and issues in judgements in which rich concepts are applied.

My being primed to go through the relevant judgement-forming procedure is constitutive of a capacity to tell by looking, under certain conditions, whether or not something is a 
sparrow, but only in certain circumstances. The same state would not constitute the capacity in circumstances in which cunningly made sparrow-like flying robots are around the place, or in which lots of birds that are not sparrows are barely distinguishable from sparrows just by looking. So the capacity in question is, more strictly speaking, a capacity to tell by looking, under certain conditions, and in certain circumstances, that something is a sparrow. The relevant circumstances are such that by-and-large the implementation of the procedure, in the right conditions, and in those circumstances, is perceptually triggered by the presence or absence of a sparrow, as the case may be, and yields a true judgement as to whether or not something is a sparrow. For the exercise of the capacity it is not enough that the judgementforming procedure should be implemented and the judgement true. ${ }^{13}$ Those conditions could be met in some Gettier-type situation. It is crucial that the presence or absence of a sparrow should, via the implementation of the procedure, lead to the true judgement that the thing seen is or is not a sparrow. Only when that happens is the capacity exercised. Nonetheless, the account allows for there to be occasions when I judge by looking that some object is or is not a sparrow and get it wrong. (These will be relatively rare if I really do have the recognitional capacity in question, since part of what is involved in having this capacity is knowing when not to be sure, and thus not to judge either way.) The account I am suggesting implies that when I get it wrong the capacity in question was not exercised. Perhaps the judgement-forming procedure that constitutes it was implemented, but unless it was triggered in the usual way by the presence or absence of a sparrow, as the case may be, the subject did not know by looking that what is seen was or was not a sparrow.

I see no prospect of providing a reductive analysis of the concept of knowing by looking. The reason is connected with our grip on what the judgement-forming procedure must be if it

\footnotetext{
${ }^{13}$ It is important for this point that the procedure runs from the having of the experiences to the making of a judgement. The presence of the object in question is not necessary for the procedure to be implemented.
} 
constitutes the capacity in question. It has to be a procedure taking suitably sensitive subjects, in suitable circumstances, and under suitable conditions, from visual experiences within some range to judgements that something is or isn't a sparrow. And it has to be a procedure the implementation of which reliably leads to true beliefs in some range of possible circumstances. But I doubt that it is possible to give a precise characterisation of the procedure or of the circumstances in which its implementation counts as the exercise of the capacity. Nonetheless, we are not in general at a loss to tell whether someone has this or that perceptual recognitional capacity. We are guided by their success or otherwise at recognising the relevant sort of object and by what they tell us about what puts them in a position to tell whether an object of that sort is or is not present.

The lack of a reductive analysis does not diminish the explanatory power of the appeal to recognitional capacities in explaining why someone knows on a particular occasion that something is so. We are interested in elucidating, for instance, what is involved in my having visual perceptual knowledge that Bill is there on a particular occasion. It is agreed pretty much on all sides that it is not enough that I should make a true judgement that he is there. On the present account what is required is that I should have exercised the relevant capacities. I could have had the relevant capacities and not exercised them, even though I made a true judgement that Bill is there. I could even make a true judgement that he is there in a circumstance in which I lack the relevant recognitional capacities. For I might simply get the feeling that it's Bill, the guy I'd heard so much about, who is standing there, and judge accordingly. So it is informative if I have made the true judgement by way of exercising the recognitional capacity. Still, it might be wondered whether the account in terms of capacities really illuminates cognitive contact. The worry here perhaps rests on the presupposition that the ultimate aim of the enquiry is a reductive analytical account of seeing and of knowing through seeing. The defender of the traditional account of experience need not accept this 
presupposition. As others have ably argued the traditional reductive analytical project in the theory of knowledge is suspect. (See especially McDowell 1995 and Williamson 2000 on this.) I do not think that this diminishes the philosophical value of the account. I have not presented the capacities I have invoked simply as those capacities, whatever they are, the exercise of which gives you this or that perceptual knowledge. On the contrary, I have presented a view of what constitutes possession of these capacities in terms of being primed to implement judgement-forming procedures in a suitable environment. The account makes explicit that the capacities in question are individuated in such a way that they do not count as being exercised unless knowledge is acquired. Because they are so individuated they can serve to explain how cognitive contact is achievable.

My approach to cognitive contact highlights one motivation for thinking that disjunctivism is an attractive view. This derives from the idea that the intrinsic character of the experiences implicated in perception should make it evident why having such experiences amounts to cognitive contact with objects or facts. This provides the motivation to think that a relational conception of experience is required to explain how perception links up with demonstrative thought, judgement, and knowledge. The disjunctivist is right to think that experiences under the traditional conception do not have an intrinsic character that will suffice to explain how perception makes demonstrative thought, judgement and knowledge possible. Where the disjunctivist goes wrong is in thinking that there is no plausible alternative, drawing upon the traditional conception of experience. There is such an alternative on which experiences under the traditional conception, possessed by subjects with appropriate cognitive capacities, contribute to the explanation of the possibility of demonstrative thought, judgement and knowledge and thus to a plausible story about what makes for cognitive contact with objects and facts. 
If I am right the gap between traditionalists and disjunctivists, at least on epistemological matters, can be narrowed. Does this mean that the difference between the traditionalist and the disjunctivist ceases to be of importance? There are three good reasons to think otherwise. The first is that the dialectical situation that I have addressed is one in which at the start there is a significant gap between the parties on experience and on knowledge. The narrowing is achieved only if the traditionalist is willing to adopt the proposed view of cognitive contact. This view has not routinely been a component in the traditionalist's battery of ideas. Though in formulating it I have been motivated by reflection on disjunctivist thinking about cognitive contact, it is not the disjunctivist's view. In particular, it does not require us to think of the experiences we have when perceiving as essentially relational. So notwithstanding the narrowing of the gap there remains a difference between the parties as to whether or not cognitive contact requires essentially relational experiences of the sort envisaged by disjunctivists. The second consideration is that it would be premature to conclude that the outstanding difference between traditionalists who embrace my view of cognitive contact and disjunctivists - the difference concerning whether perceptual experiences are essentially relational-is of no significance. Disjunctivists think that epistemological danger lurks if it is conceded to the traditionalist that perception implicates experiences under the traditional conception. On the view I have presented, which traditionalists may adopt, there is no such danger. That looks like a significant difference. The third consideration is that it is not only epistemology that has divided disjunctivists and traditionalists about experience. There are issues in the philosophy of mind about the very intelligibility of the traditional conception, which I have not explored here. ${ }^{14}$ Even if the difference between traditionalists and

\footnotetext{
${ }^{14}$ I have in mind the sorts of issues explored in Martin 2004.
} 
disjunctivists on experience were a side-show so far as epistemology is concerned, it would remain an open question what these further issues amount to. ${ }^{15}$

\section{BIBLIOGRAPHY}

Alston, William P. (1999) 'Perceptual Knowledge' in John Greco and Ernest Sosa (eds.) The Blackwell Guide to the Theory of Knowledge, Oxford: Blackwell, 1999, 223-42.

Audi, Robert (2003). Epistemology: A Contemporary Introduction to the Theory of Knowledge. London: Routledge.

Ayers, Michael (2001). 'What is Realism'. Aristotelian Society, Supplementary Volume 75, $91-110$.

Bach, Kent (1982). 'De re Belief and Methodological Solipsism', in Andrew Woodfield (ed.) Thought and Object: Essays on Intentionality. Oxford: Clarendon Press.

Brewer, Bill (1999). Perception and Reason. Oxford: Clarendon Press.

Campbell, John (2002). Reference and Consciousness. Oxford: Clarendon Press.

Child, William (1994). Causality, Interpretation and the Mind. Oxford: Clarendon Press.

Dretske, Fred (1993) 'Conscious Experience'. Mind 102, 264-83.

Evans, Gareth (1982). The Varieties of Reference. Oxford: Clarendon Press

Fish, William (2005) 'Disjunctivism and Non-Disjunctivism: Making Sense of the Debate', Proceedings of the Aristotelian Society, 105, 2005, 119-27.

Fodor, Jerry. A. (1987). Psychosemantics. Cambridge, MA.: MIT Press.

Foster, John (2000). The Nature of Perception. Oxford: Oxford University Press.

\footnotetext{
${ }^{15}$ I am grateful to audiences at the Universities of Glasgow, St Andrews and Sheffield for discussion of an earlier version of this article and to conversations with Duncan Pritchard, Adrian Haddock, and Fiona Macpherson. I am grateful also to comments on an earlier version by a referee, which led to clarifications at crucial points.
} 
Grice, H. P. (1961). 'The Causal Theory of Perception'. Aristotelian Society, Supplementary Volume 35, 121-52.

Hinton, J. M. (1973). Experiences. Oxford: Clarendon Press.

Hyman, John (1992). 'The Causal Theory of Perception'. The Philosophical Quarterly 42, 277-96.

Hyman, John (1994) 'Vision and Power'. The Journal of Philosophy 91, 236-52.

Johnston, M. (2004). 'The Obscure Object of Hallucination'. Philosophical Studies 120, 113 83.

Martin, M. G. F. (2004). 'The Limits of Self-Awareness'. Philosophical Studies 120, 37-89. McDowell, John (1982). 'Criteria, Defeasibility, and Knowledge'. Proceedings of the British Academy 68, 455-79. References are to the version in McDowell 1998.

McDowell, John (1986). 'Singular Thought and the Extent of Inner Space' in Philip Pettit and John McDowell (eds.) Subject, Thought, and Context. Oxford: Clarendon Press, 13768. References are to the version in McDowell 1998.

McDowell, John (1995). 'Knowledge and the Internal'. Philosophy and Phenomenological Research 55. 877-93. References are to the version in McDowell 1998.

McDowell, John (1998). Meaning, Knowledge, and Reality. Cambridge, MA.: Harvard University Press.

Millar, Alan (1996), 'The Idea of Experience' Proceedings of the Aristotelian Society 96, 7590.

Millar, Alan (forthcoming). 'Disjunctivism and Scepticism' in The Oxford Handbook to Scepticism (Oxford: Oxford University Press).

Moore, G. E. (1953) Some Main Problems of Philosophy (London: Allen and Unwin).

Pears, D. F. (1976). 'The Causal Conditions of Perception', Synthese 33, 25-40.

Pollock, J. (1987). Contemporary Theories of Knowledge. London: Hutcheson. 
Putnam, Hilary (1994) 'Sense, Nonsense, and the Senses: An Inquiry into the Powers of the Human Mind'. The Journal Of Philosophy 91, 445-517.

Robinson, Howard (1990) 'The Objects of Perceptual Experience'. Aristotelian Society, Supplementary Volume 64, 151-66.

Robinson, Howard (1994) Perception. London: Routledge.

Searle, John (1983) Intentionality. Cambridge: Cambridge University Press.

Smith, A. D. (2002) The Problem of Perception. Cambridge, MA.: Harvard University Press. Smith, Peter (1990/91) 'On "The Objects of Perceptual Experience"'. Proceedings of the Aristotelian Society 91, 191-96.

Snowdon, Paul (1980/81) 'Perception, Vision and Causation'. Proceedings of the Aristotelian Society 81, 175-92.

Snowdon, Paul (1990) 'The Objects of Perceptual Experience'. The Aristotelian Society, Supplementary Volume 64, 121-50.

Snowdon, Paul (1992) 'How to Interpret "Direct Perception"” in Tim Crane (ed.) The Content of Experience Cambridge: Cambridge University Press, 48-78.

Snowdon, Paul (2002) 'What is Realism'. Proceedings of the Aristotelian Society 102, 20128.

Snowdon, Paul (2005) 'The Formulation of Disjunctivism: A Response to Fish', Proceedings of the Aristotelian Society, 105, 2005, 129-41.

Strawson, P. F. (1974) 'Causation in Perception', in Strawson's Freedom and Resentment. London: Methuen.

Strawson, P. F. (1979) 'Perception and Its Objects' in G. F. Macdonald (ed.) Perception and Identity. London: Macmillan.

Sturgeon, Scott (2000) Matters of Mind: Consciousness, reason and nature. London: Routledge. 
Thau, M. (2004) 'What is Disjunctivism?'. Philosophical Studies 120, 193-253.

Williamson, Timothy (2000) Knowledge and Its Limits. Oxford: Oxford University Press. 